\title{
DESIGN AND ANALYSIS OF COIL SPRING IN VEHICLES USING
}

\section{FINITE ELEMENTS METHOD}

\author{
ASSAAD ALSAHLANI ${ }^{1}$, MOHAMMED K. KHASHAN ${ }^{2}$ \& HAYDER H. KHALEEL ${ }^{3}$ \\ ${ }^{1,3}$ Engineering Technical College / Najaf, Al- Furat Al-Awsat Technical University, Al-Najaf, Iraq \\ ${ }^{2}$ Najaf Technical Institute, Al-Furat Al-Awsat Technical University, Al-Najaf, Iraq
}

\begin{abstract}
Suspension system plays a very important role in new vehicles. Its duty is to damp, smooth out the shock impulse furthermore to absorb or dissipate energy so that the suspension system provides the comfort and safety for the passengers and vehicles. In this paper, the simulation of spring is carried out by using Solid works 2018 with specific dimensions and analysis it with finite element analyzer ANSYS 14. Three materials are selected to simulate the spring steel, copper alloy, and carbon composite. The deformation, strain, stress and shear stress are obtained numerically under various values of load $(1500,2000$ and 2500) $N$. The results showed that the deformation in carbon composite is less than steel and copper alloy so that the carbon composite is the best material for helical spring and can withstand the load and deflection.
\end{abstract}

KEYWORDS: Coil spring, Suspension System, Stress, Steel, Copper Alloy, Carbon Composite \& ANSYS 14

Received: May 18, 2018; Accepted: Jun 23, 2018; Published: Jul 17, 2018; Paper Id.: IJMPERDAUG201864

\section{INTRODUCTION}

The suspension system one of the most important components in the automobile, it is responsible for dissipating the kinetic energy and controlling the shock. In automobiles, shock absorber decreases the influence of traveling over the harsh road which is leading to improve the vehicle control and the quality of the ride. The suspension system consists of many parts like axles, shock absorber, springs, ball joints and arm rods. The spring is flexible part of the system and it can be defined as the elastic body, which deforms when it subjected to load and returns to its original shape when the load diminishes. New passengers' automobiles have light coil springs. Commercial automobiles have coil spring in the front and leaf spring in the rear. Coil spring is manufactured from the particular wire, which is treated with heat to produce the desired shape. The ability of spring to withstand the load depends on its shape, the total diameter of spring and the diameter of the wire. The failure of the spring may occur because of the poor properties of materials of spring in addition to high cyclic fatigue.

Many studies have been analyzed the behavior of spring in the automobiles. N. Lavanya et al presented an analysis of the safe load for light automobiles suspension spring which is fabricated from two materials chrome vanadium steel and low carbon steel. The results showed that the low carbon steel is suitable more than the chrome vanadium steel for production of helical spring [1]. K. Vinay Kumar, R. Rudrabhiramu chose three different materials for the spring stainless steel, alloy steel and chromium vanadium and the load on the spring with the steady load. The research calculated numerically and theoretically the stress and deformation. The study concluded 
that alloy steel was preferred in fabrication the spring because it could withstand the deformation occurred in spring [2]. A. Chinnamahammad Bhasha modeled 3D spring with Catia and analyzed it with Analysis. Different materials were chosen to simulate the spring like Titanium alloy, Phosphor bronze, Spring Steel and Beryllium Copper. Many parameters were taken into consideration during the analysis process such as weight and load. The study determined the displacement for many frequencies. It can be observed from the results that the Titanium alloy is the best material for spring [3]. Logavigneshwaran S. the object of this study was analysis and design of the performance of shock absorber due to the change in the diameter of the wire of coil spring to check the suitable diameter of the spring. The simulation was carried out by using Ansys [4]. Aakash Bhatt et al studied the helical coil spring with two different materials E-Glass and steel. It could be concluded that E- Glass is better than the steel because it reduced the weight of spring [5]. Harshal Rajurakar and M. C. Swami this paper offered an analysis of helical spring made of chrome vanadium and hard carbon steel for rectangular and circular cross section were studied by using FEM. The deflection and shear stress were gotten. It can be observed from the results that the chrome vanadium could withstand the deflection better than hard carbon steel [6]. Karthik et al designed shock absorber with ANSYS 14.5 using different materials like aluminum alloy, steel structure, titanium alloy and copper alloy. The results showed that the stress and deformation for spring made of titanium is less in contrast with other materials [7]. Vijayeshwar compared between two helical springs manufactured of hard drawn carbon steel and chrome silicon by using ANSYS 15 to determine the suitable materials for coil spring that could reduce the stress and deformation. The results approved that the deformation in chrome silicon is less than the hard drawn carbon steel and it was less in weight with high stiffness [8]. Khutbuddin Shaikh and Asma Naser presented an experimental, analytical and finite element study of helical spring in order to estimate the deformation and stress. It is observed that there was a linear relationship between the deflection and applied load [9].

The goal of this paper is to model and analysis of spring of the suspension system in the automobiles with three different materials steel, copper alloy, and carbon composite. The simulation of spring is carried out by using Solidworks 2018 with specific dimensions and analysis it ANSYS 14. The deformation, strain, stress and shear stress are obtained numerically with different values of load (1500, 2000 and 2500) N.

\section{METHODOLOGY}

In this study, the simulation and analysis of coil spring were done with different materials. The materials selected were steel structure, copper alloy, and carbon composite. The coil spring was simulated with Solidworks 2018 with specific dimensions which are listed in Table 1.

Table 1: The Specifications of Coil Spring

\begin{tabular}{|c|l|c|}
\hline No. & \multicolumn{1}{|c|}{ Specification } & Value \\
\hline 1 & Outside diameter & $88 \mathrm{~mm}$ \\
\hline 2 & Inside diameter & $64 \mathrm{~mm}$ \\
\hline 3 & Wire diameter & $12 \mathrm{~mm}$ \\
\hline 4 & Free length & $315 \mathrm{~mm}$ \\
\hline 5 & Number of active coil & 12 \\
\hline 6 & Pitch & $25 \mathrm{~mm}$ \\
\hline
\end{tabular}

The coil spring shown in Figure 1 


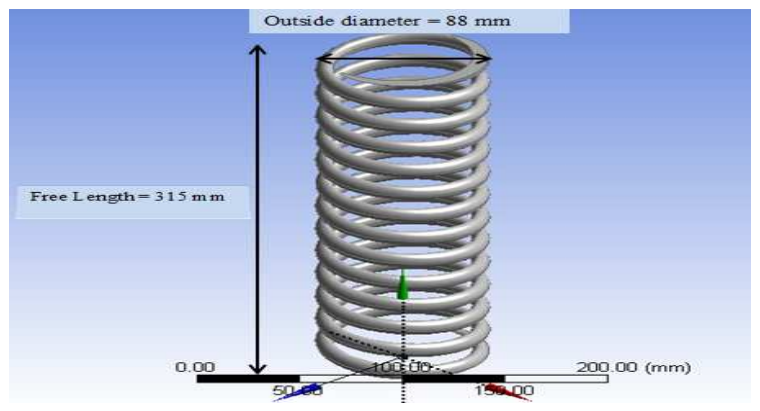

Figure 1: The Coil Spring

The properties of materials used for producing the coil spring in this paper listed in Table 2.

Table 2: Properties of Materials

\begin{tabular}{|l|c|c|c|}
\hline \multicolumn{1}{|c|}{ Materials } & Steel Structure & Copper Alloy & $\begin{array}{c}\text { Carbon } \\
\text { Composite }\end{array}$ \\
\hline Density & $7850 \mathrm{~kg} / \mathrm{m}^{3}$ & $8300 \mathrm{~kg} / \mathrm{m}^{3}$ & $1600 \mathrm{~kg} / \mathrm{m}^{3}$ \\
\hline Young modulus & $2 \mathrm{E}+11 \mathrm{pa}$ & $1.1 \mathrm{E}+11 \mathrm{pa}$ & $2.28 \mathrm{E}+11 \mathrm{pa}$ \\
\hline Poisson ratio & 0.3 & 0.34 & 0.28 \\
\hline
\end{tabular}

The numerical analysis was done by using finite elements analyzer ANSYS 14. The spring has meshed with the number of nodes was 224030 and number of elements was 138201. The mesh of coil spring shown in Figure 2.

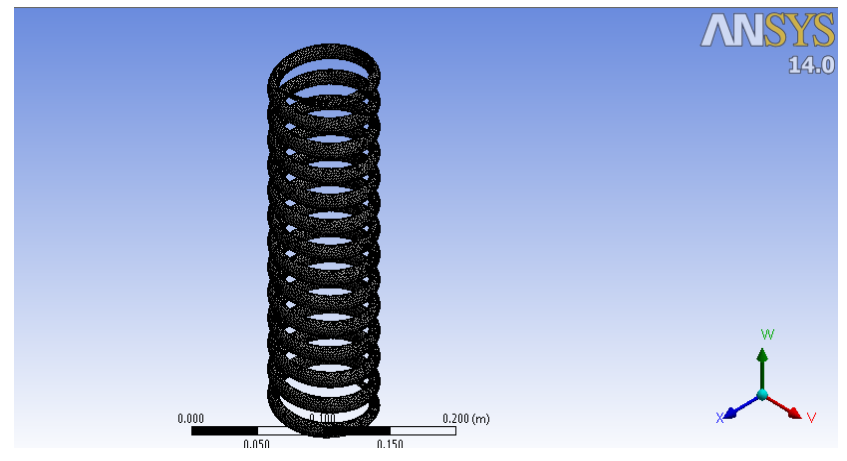

Figure 2: The Mesh of Coil Spring

The spring was fixed in the bottom end and the load was subjected on the upper end with different values (1500, 2000, 2500) $\mathrm{N}$ in order to get the total deformation, stress, strain and shear stress. The analysis was carried out with static analysis in ANSYS 14. The analysis steps could be summarized as the flow chart in Figure 3.

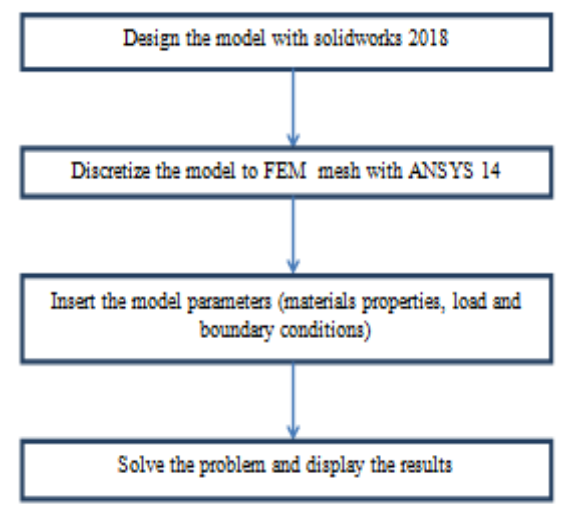

Figure 3: Flow Chart for Analysis Process 


\section{RESULTS}

The total deformation, stress according to von - Mises theory, strain and shear stress were obtained numerically for the three materials with various values of the load in order to compare between them and choose the best material that can be used in the production process of the coil or helical spring in modern automobiles.

For the value of load $(1500 \mathrm{~N})$ the maximum total deformation happened in spring made of copper alloy and it was (448 mm) as shown in Figure 4 below.

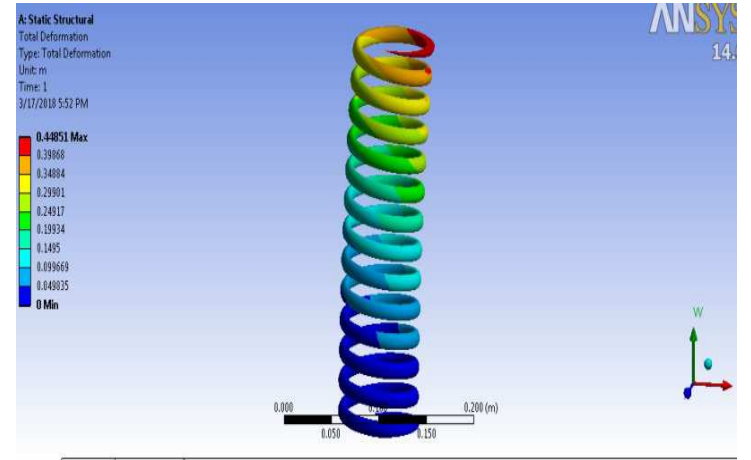

Figure 4: Total Deformation in Spring Made of Copper Alloy

While the minimum total deformation happened in spring made of carbon composite and the value was (206 $\mathrm{mm})$ as shown in Figure 5 below

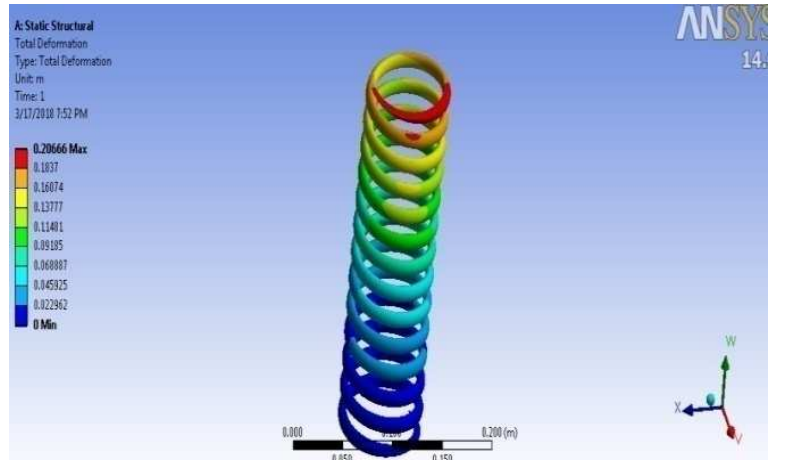

Figure 5: Total Deformation in Spring Made of Carbon Composite

For the stress, under load $(1500 \mathrm{~N})$ the maximum stress according to von-mises theory occurred in spring made of steel structure and the value was $(2.825 \mathrm{Gpa})$ as shown in Figure 6 below.

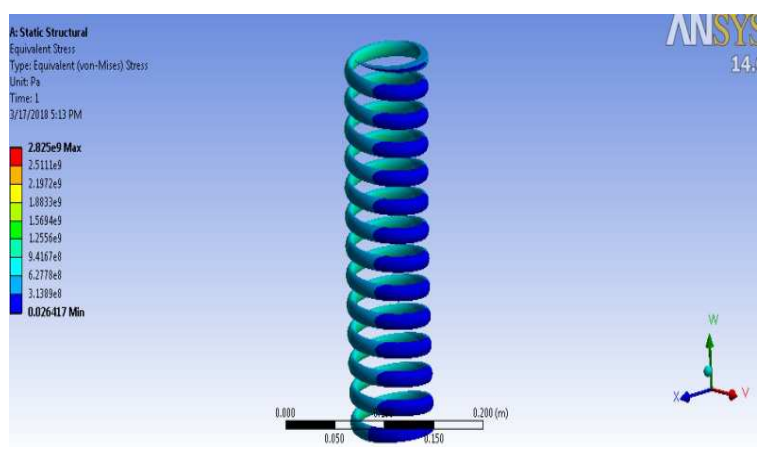

Figure 6: The Stress in Spring Made of Steel Structure 
The minimum value of stress under load (1500) $\mathrm{N}$ happened in carbon composite with the value (2.44Gpa) as shown in Figure 7.

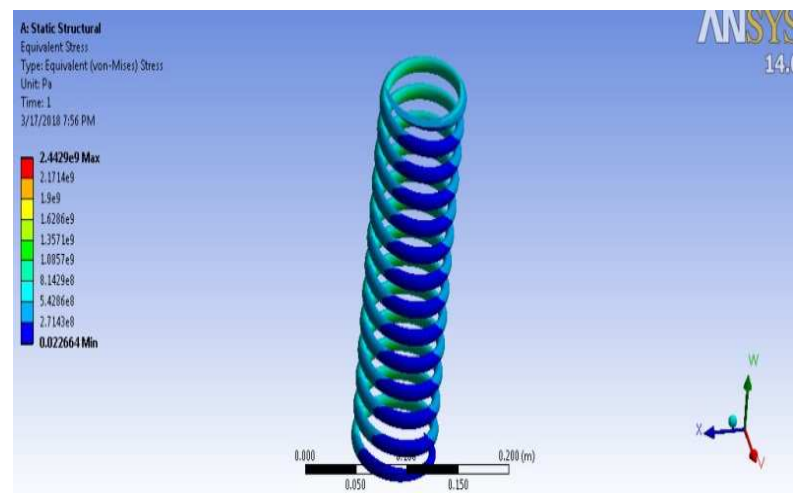

Figure 7: The Stress in Spring Made of Carbon Composite

For the strain under load $(1500 \mathrm{~N})$ the maximum strain occurred in spring with copper alloy with value $(23.40 \mathrm{~m} \mathrm{~m} / \mathrm{mm})$ as shown in Figure 8 below.

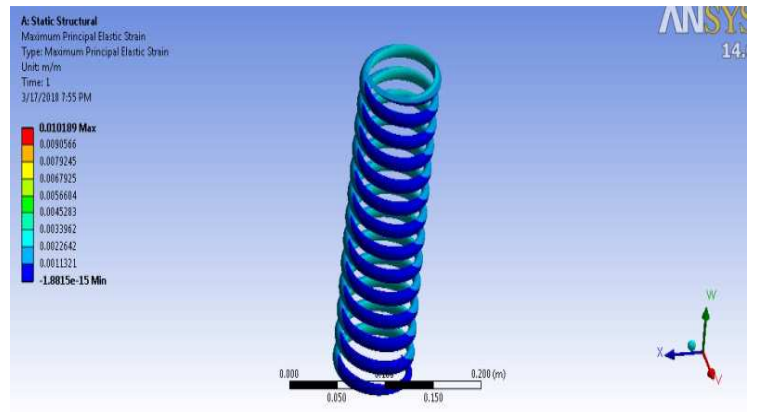

Figure 8: The Strain in Spring Made of Copper Alloy

The minimum strain occurred in spring made of carbon composite and the value of strain was $(10.1 \mathrm{~mm} / \mathrm{mm})$ as shown in Figure 9 below.

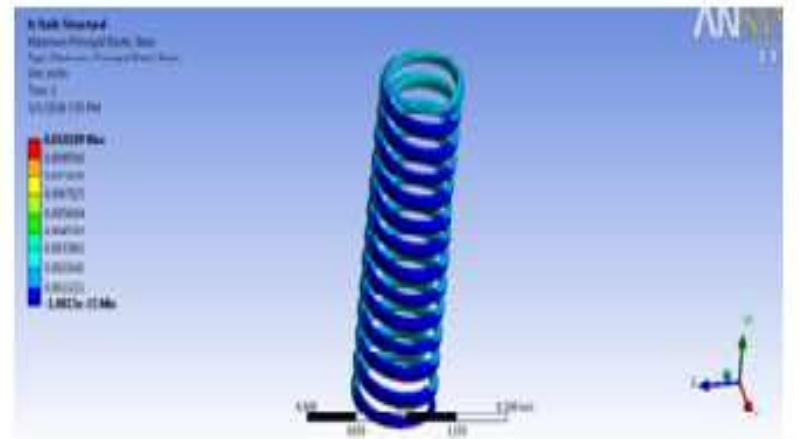

Figure 9: The Strain in Spring Made of Carbon Composite

For the shear stress under $(1500 \mathrm{~N})$ approximately was the same for the three materials and the maximum shear stress occurred in spring with carbon composite and the value was $(0.453 \mathrm{Gpa})$ as shown in Figure 10 below. 


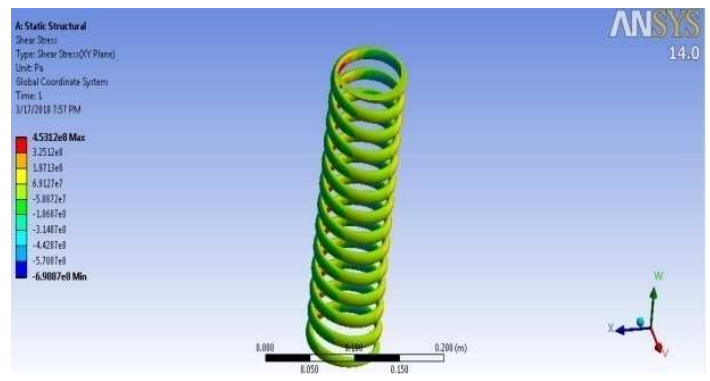

Figure 10: Shear Stress in Spring Made of Carbon Composite

The minimum shear stress under $(1500 \mathrm{~N})$ occurred in spring with copper alloy and the value was $(0.452 \mathrm{Gpa})$ as shown in Figure 11 below.

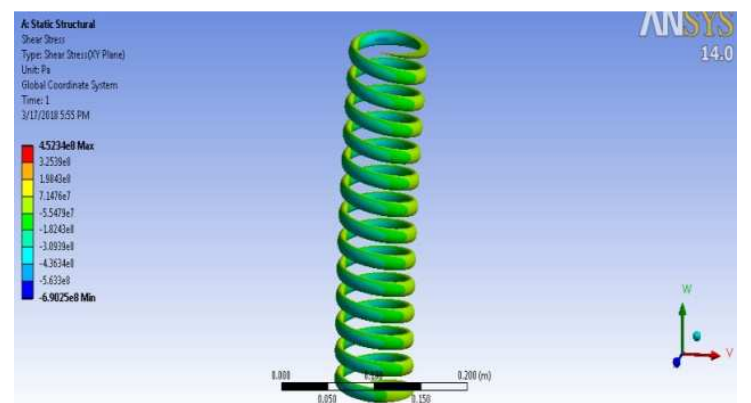

Figure 11: Shear Stress in Spring Made of Copper Alloy

The results (total deformation, stress, strain and shear stress) for different loads (1500) $\mathrm{N}$ for the three materials could be summarized in a Table 3 below

Table 3: Results for Load (1500) $\mathrm{N}$

\begin{tabular}{|l|c|c|c|c|c|}
\hline \multicolumn{1}{|c|}{ Material } & $\begin{array}{c}\text { Load } \\
(\mathbf{N})\end{array}$ & $\begin{array}{c}\text { Total } \\
\text { Deformation } \\
(\mathbf{m m})\end{array}$ & $\begin{array}{c}\text { Stress } \\
(\mathbf{G p a})\end{array}$ & $\begin{array}{c}\text { Strain } \\
(\mathbf{m m} / \mathbf{m m})\end{array}$ & $\begin{array}{c}\text { Shear } \\
\text { Stress } \\
(\mathbf{G p a})\end{array}$ \\
\hline Steel Structure & 1500 & 241 & 2.82 & 13 & 0.4525 \\
\hline Copper Alloy & 1500 & 448.1 & 2.807 & 23.4 & 0.4523 \\
\hline Carbon Composite & 1500 & 206.6 & 2.44 & 10.1 & 0.4531 \\
\hline
\end{tabular}

The results (total deformation, stress, strain and shear stress) for different loads (2000) $\mathrm{N}$ for the three materials could be summarized in a Table 4 below.

Table 4: Results for Load (2000) N

\begin{tabular}{|l|c|c|c|c|c|}
\hline \multicolumn{1}{|c|}{ Material } & $\begin{array}{c}\text { Load } \\
(\mathbf{N})\end{array}$ & $\begin{array}{c}\text { Total } \\
\text { Deformation } \\
(\mathbf{m m})\end{array}$ & $\begin{array}{c}\text { Stress } \\
(\mathbf{G p a})\end{array}$ & $\begin{array}{c}\text { Strain } \\
(\mathbf{m m} / \mathbf{m m})\end{array}$ & $\begin{array}{c}\text { Shear } \\
\text { Stress } \\
(\mathbf{G p a})\end{array}$ \\
\hline Steel structure & 2000 & 321.5 & 3.766 & 17.4 & 0.603 \\
\hline Copper alloy & 2000 & 598 & 3.743 & 31.2 & 0.6031 \\
\hline Carbon composite & 2000 & 275.5 & 3.257 & 13.5 & 0.641 \\
\hline
\end{tabular}

The results (total deformation, stress, strain and shear stress) for different loads (2500) $\mathrm{N}$ for the three materials could be summarized in a Table 5 below. 
Table 5: Results for Load (2500) N

\begin{tabular}{|l|c|c|c|c|c|}
\hline \multicolumn{1}{|c|}{ Material } & $\begin{array}{c}\text { Load } \\
(\mathbf{N})\end{array}$ & $\begin{array}{c}\text { Total } \\
\text { Deformation } \\
(\mathbf{m m})\end{array}$ & $\begin{array}{c}\text { Stress } \\
(\mathbf{G p a})\end{array}$ & $\begin{array}{c}\text { Strain } \\
(\mathbf{m m} / \mathbf{m m})\end{array}$ & $\begin{array}{c}\text { Shear } \\
\text { Stress } \\
(\mathbf{G p a})\end{array}$ \\
\hline Steel structure & 2500 & 401.8 & 4.708 & 21.7 & 0.754 \\
\hline Copper alloy & 2500 & 747.5 & 4.679 & 39.1 & 0.739 \\
\hline Carbon composite & 2500 & 344.4 & 4.071 & 17 & 0.755 \\
\hline
\end{tabular}

The comparison of total deformation at various values of load for the three materials shown in Figure.12

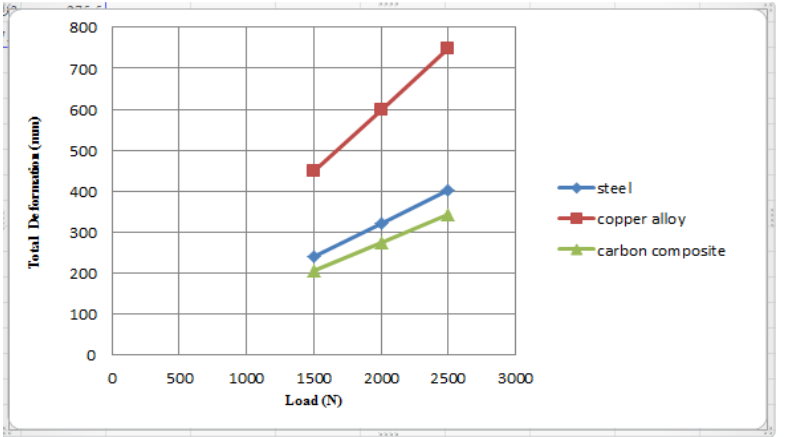

Figure12: Total Deformation (mm) vs. Load (N)

The comparison of stress at various values of load for the three materials shown in Figure 13.

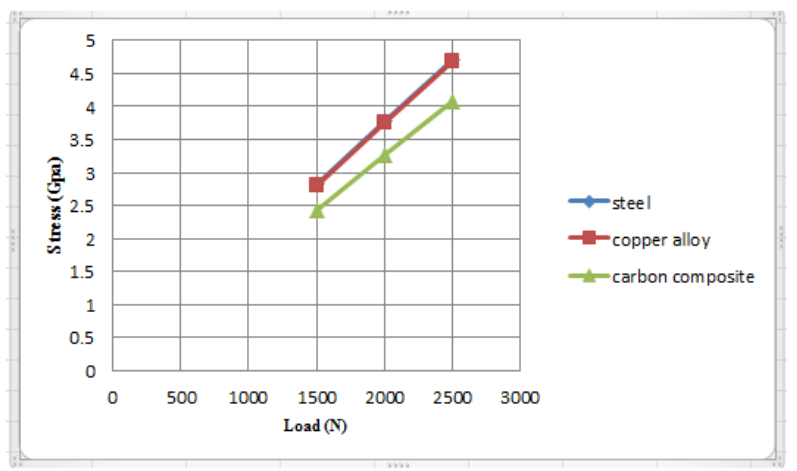

Figure 13: Stress (Gpa) vs. Load (N)

The comparison of strain at various values of load for the three materials shown in Figure 14.

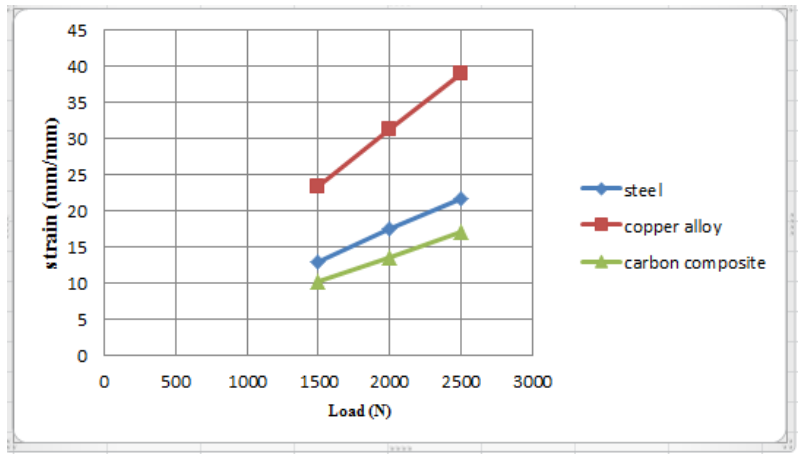

Figure 14: Strain $(\mathrm{mm} / \mathrm{mm})$ vs. Load $(\mathrm{N})$

The comparison of shear stress at various values of load for the three materials shown in Figure.15 


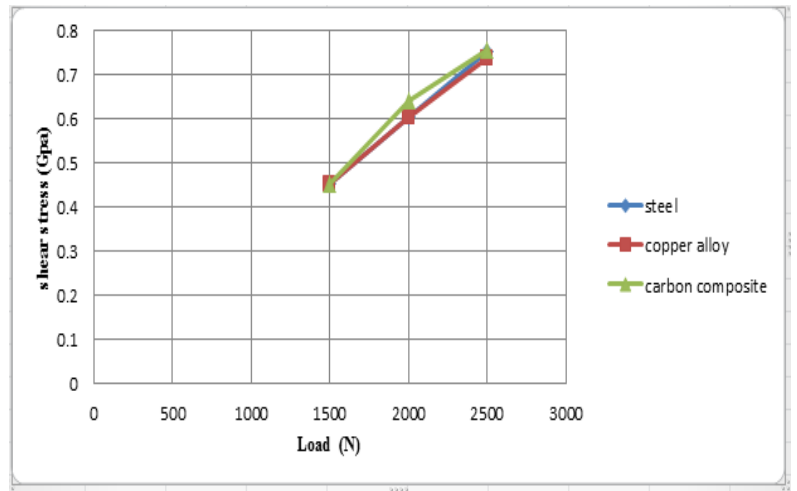

Figure 15: Shear Stress (Gpa) vs. Load (N)

\section{CONCLUSIONS}

In this study, the simulation and analysis of coil or helical spring which is the main part in the suspension system in modern vehicles were carried out by using Solid works 2018 and ANSYS 14. Three different materials were chosen to manufacture the spring under various values of load. The results showed that the less value of total deformation happened in spring made of carbon composite for all the values of load. The deformation reduced by $15 \%$ in carbon composite comparing with the deformation in steel and reduced by about 54\% comparing with total deformation in copper alloy. The deformation, strain stress and shear stress increased by increasing the load. The stress and shear stress approximately the same for the three materials under the same load. It could be concluded that the carbon composite is the suitable material to fabricate the coil spring in the suspension system in automobiles. Carbon composite has many advantages for the suspension system such as reduce the weight and strength to the system in spite of its cost. For the future work, it is recommended to simulate the coil spring with different materials and various load and change the type of spring from the coil to leaf spring in addition to change the dimensions of spring such as the outside diameter, free length, pitch etc.

\section{REFRENCES}

1. N. Lavanya, P. Sampath Rao and M. Pramod Reddy, "Design and Analysis of A Suspension Coil Spring For Automotive Vehicle” Int. Journal of Engineering Research and Applications, Vol. 4, Issue 9( Version 5), September 2014, pp.151-157.

2. K. Vinay Kumar, R. Rudrabhiramu, "Design And Analysis of Helical Springs in Two Wheeler Suspension System" International Journal of Research in Advanced Engineering Technologies, Volume 5, Issue 2 DEC 2015

3. A. Chinnamahammad bhasha, N. Vijay rami reddy and B. Rajnaveen "Design and Analysis of Shock Absorber" International Research Journal of Engineering and Technology (IRJET) Volume: 04 Issue: 01 Jan -2017.

4. Logavigneshwaran S., Sriram G and Arunprakash R. "Design and Analysis of Helical Coil Spring in Suspension System" International Journal for Trends in Engineering \& Technology, Volume 9 Issue 1 - September 2015 - ISSN: 2349 - 9303

5. Aakash Bhatt, Anil Devani and Parth Zalavadiya, "Design analysis of helical spring of suspension System" IJEDR |Volume 4, Issue 3. 2016

6. Harshal Rajurakar, M. C. Swami “Analysis Of Helical Compression Spring For Two Wheeler Automotive Rear Suspension” Journal of Mechanical and Civil Engineering (IOSR-JMCE) Volume 13, Issue 2 Ver. II (Mar. - Apr. 2016)

7. Karthik A. S., Manojkumar M. Hanumanalli, Vinaykumar B. Honakeri, Manjunath S. "Design and Static Analysis of Shock Absorber" IJIRST -International Journal for Innovative Research in Science \& Technology| Volume 2 | Issue 12 | May 2016 ISSN (online): 2349-6010 
8. Vijayeshwar BV, Preetham B M, Bhaskar U "Design and Static Analysis of Helical Suspension Spring with Different Materials" International Advanced Research Journal in Science, Engineering and Technology, Vol. 4, Special Issue 7, May 2017

9. Zeeshan Khutbuddin Shaikh and Sayyad Asma Naser "Experimental Study of Helical Compression Spring” International Journal of Engineering Technology Science and Research, Volume 4, Issue 12, December 2017. 
